\title{
REVIEW \\ Against all odds: a qualitative study of rehabilitation of persons with spinal cord injury in Afghanistan
}

\author{
M Michael ${ }^{1}$ and K Roth ${ }^{2}$
}

\begin{abstract}
Study design: Cross-sectional, survey.
Objectives: To describe the challenges in rehabilitating patients with spinal cord injury (SCI) in the orthopaedic centres of the International Committee of the Red Cross (ICRC) in Afghanistan.

Setting: Afghanistan (Kabul, Herat, Mazar-i-Sharif, Jalalabad, Gulbahar), April 2012.

Methods: Semi-structured interviews were conducted with managers and professional staff of ICRC and other concerned organizations/institutions (Ministries, hospitals, non-governmental organizations), and with people with $\mathrm{SCl}$ and their families. Quantitative data were extracted from routine statistics.

Results: A reported annual incidence of roughly $21 \mathrm{SCl}$ cases per million in Afghanistan could be established for the year 2011 . Acts of violence were the most frequent cause, followed by spinal tuberculosis. Despite very elementary prehospital and hospital care, SCI individuals are rehabilitated within the limits set by available technology and socio-economic factors. Support to community reintegration is effective for the ones living within a radius determined by distance and security.

Conclusion: Rehabilitation of SCl patients would be ineffective without covering at least part of the services usually provided during the phases of acute hospital care and community reintegration. The question of whether services currently provided by foreign-based or funded organizations can be extended into a potential postconflict period, and by whom, remains open.
\end{abstract}

Spinal Cord (2012) 50, 864-868; doi:10.1038/sc.2012.113; published online 2 October 2012

Keywords: spinal cord injury; demography; epidemiology; rehabilitation; Afghanistan; public health strategies

\section{INTRODUCTION}

Our knowledge about spinal cord injury (SCI) in the developing world is still limited when compared with what we know about it in developed world. Rathore ${ }^{1}$ summarizes what we do know: SCI is primarily a disease of young males and most frequently caused by trauma (similarities with the developed world stop here). Prehospital care is liable to aggravate the lesion, treatment in specialized spinal cord units is a rarity and rehabilitation medicine is poorly developed. Morbidity through complications is very high and shortens the life span of SCI individuals very significantly due to deaths by kidney failure. Community integration is difficult, owing to stigma and ineffective public policies.

Afghanistan is a poor country, at war since over 3 decades; it is presently caught in a 'transition without end'.2 Uptake of public health service provision has been slower than that expected-patients still prefer the unregulated private sector and the ones who can afford it seek hospital care abroad. The Ministry of Public Health (MoPH) is fragmented and donor-dependent. ${ }^{3}$

Programmes concerned with rehabilitation and community reintegration of individuals with SCI are implemented by a few foreignbased or foreign-funded non-governmental organizations (NGOs), namely Handicap International (HI), the Swedish Committee for Afghanistan (SCA), International Assistance Mission (IAM) and Kabul Orthopaedic Organization (KOO), and by the International Committee of the Red Cross (ICRC). In 2011, the latter rehabilitated
$75 \%$ of all SCI patients newly registered in Afghanistan $(N=638)$ in its six regional orthopaedic centres (whose core business is prosthetics for amputees). The present study follows a similar one conducted in Kabul and Herat 11 years ago; ${ }^{4}$ it aims to contribute narrowing the knowledge gap regarding rehabilitation of individuals with SCI in developing countries by illustrating and analysing the difficulties and opportunities in a specific environment with multiple constraints.

\section{MATERIALS AND METHODS}

The cross-sectional survey was conducted in Afghanistan in April 2012. Methods employed were literature research, semi-structured individual interviews, and observation (of clinical activities in rehabilitations centres and living conditions during home visits). Respondents for interviews were chosen among a purposeful sample of managers and professional staff of ICRC and other concerned organizations/institutions (Ministries, Hospitals and NGOs; $N=60)$ and a sample of people with SCI chosen at random among ICRC's clients ( $N=51$, at times including family members), who were interviewed in hospitals, rehabilitation centres or in their homes. Places visited were: Kabul, Herat, Mazar-i-Sharif, Jalalabad and Gulbahar. Quantitative data were extracted from ICRC's yearly statistics, admission registers and patient records, and information on yearly statistics provided by the other organizations mentioned. The major limitation of this study was the perimeter for home visits to people with SCI, confined to districts considered 'safe'. This sample bias is partially offset through interviews with patients in orthopaedic centres living in 'unsafe' districts.

${ }^{1}$ International Committee of the Red Cross, Health Unit, São Paulo, Brazil and ${ }^{2}$ Swiss Paraplegics Centre, Nursing Care, Nottwil, Switzerland 


\section{RESULTS}

Policies

Services to be provided for people with disabilities by the public sector at primary and secondary health-care level are included in the respective policy documents and service profiles. ${ }^{5,6}$ Owing to the lack of specialized skills and services in the public sector, however, implementation has largely been left to the private non-profit sector. The Afghan Constitution ${ }^{7}$ stresses equal rights for disabled persons; the National Disability Action $\mathrm{Plan}^{8}$ stipulates welfare payments, and the cited National Development Strategy ${ }^{9}$ aims at mainstreaming of disability into national policies, programs and projects. Very few of these measures have been implemented so far.

\section{Epidemiology}

As data on SCI in Afghanistan are not part of the routine health information system of the MoPH, their availability is limited; the national disability survey conducted in $2005^{10}$ did not disaggregate between kinds of disability.

The four major SCI rehabilitation organizations (HI, SCA, IAM, $\mathrm{KOO}$ and ICRC) provided a (self-reported) figure of 638 new cases of SCI in their centres for 2011, which corresponds to a reported annual incidence of SCI of roughly 21 SCI cases per million (based on a population estimate of $30 \mathrm{~m}$ ), without allowing for underreporting (of those who died before seeking rehabilitation services and those who never sought them). The number of SCI patients admitted into ICRC's six orthopaedic centres has levelled off at a magnitude of roughly 500 per year. The aetiology of SCI among all its 478 new cases in 2011-of which $48(10 \%)$ are paraplegic and 430 (90\%) are tetraplegic-is described in Table 1; Table 2 lists the type of lesion among the same sample of patients.

Table 1 Aetiology of spinal cord injury among all patients newly admitted by the International Committee of the Red Cross (ICRC) in 2011

\begin{tabular}{lcc}
\hline Cause & Number of patients & $\%$ \\
\hline Non-traumatic & 78 & \\
$\quad$ Tuberculosis & 99 & 16.3 \\
Other non-traumatic & 177 & 20.7 \\
Subtotal & & 37 \\
& & \\
Traumatic & 65 & 13.6 \\
Fall from height & 31 & 6.5 \\
Road traffic accident & 82 & 17.2 \\
Act of violence & 123 & 25.8 \\
Other traumatic & 301 & 63 \\
Subtotal & 478 & 100 \\
Total & & \\
\hline
\end{tabular}

Table 2 Type of lesion among new admissions of individuals with spinal cord injury for rehabilitation by the International Committee of the Red Cross in 2011

\begin{tabular}{lccr}
\hline & Complete lesion (\%) & Incomplete lesion (\%) & Total (\%) \\
\hline Tetraplegic & $37(77)$ & $11(23)$ & $48(100)$ \\
Paraplegic & $285(66)$ & $145(34)$ & $430(100)$ \\
Total & $322(67)$ & $156(33)$ & $478(100)$
\end{tabular}

aCRC does not use the latest definition of (in)complete lesions yet, as in Kirshblum et al. ${ }^{38}$ Its classification of patients is based on the definition of a complete lesion as 'no motor or sensory function below the level of lesion, including the lowest sacral segments S4-5'.
Pressure ulcers and urinary tract infections (UTIs) are common secondary conditions in Afghanistan. More than half of all newly admitted SCI patients by ICRC in 2011 presented with pressure ulcers. The vast majority of SCI patients 'hospitalized' in its centres are treated there for pressure ulcers, for a duration of up to 6 months. The result of treatments (mostly conservative, only in few cases involving plastic surgery) is generally satisfactory. No data on incidence of UTIs were available; anecdotal evidence, however, points at kidney failure as the most frequent single cause of mortality: $44.8 \%$ reported in Kabul among the sample of all 145 registered deaths between 2000 and 2011. Depression appears to occur, for example among women abandoned by their husbands or men who had to put up with being a burden on their families. Thromboembolic complications appear very rare or severely underreported owing to limited possibility for diagnostic investigation.

\section{Prehospital and hospital care}

No medically equipped and professionally staffed ambulance service exists in Afghanistan outside the Armed Forces. Patients suffering heavy injuries are taken to a hospital—if at all-by all sorts of local transportation means available and without use of known preventive measures. Acute hospital care appears equally deficient in caring for the needs of patients with SCI. Specific therapeutic measures applied in developing countries, such as early steroid infusions, are not available. Specialized SCI services do not exist in Afghanistan; general hospitals tend to refer patients to 'tertiary' hospitals in Kabul or immediately to Pakistan. Surgery for spinal fixation is then often performed in these hospitals.

Diagnostic means are limited: although general hospitals have $\mathrm{X}$-ray machines, CT scan is available in major cities only and magnetic resonance imaging only in Kabul, both in the private sector. The potential for clinical diagnose is not used, either (the level of spinal injury and of remaining and lost functions is rarely diagnosed); the bladder function is not investigated even in 'tertiary' hospitals with a urology department. Beyond the application of an indwelling urinary catheter, no measures are taken during acute hospitalization to prevent other secondary conditions such as pressure ulcers or contractions. Routine physiotherapy and nursing care (such as changing position to avoid pressure ulcers) are nonexistent. Referral from hospitals to rehabilitation services is not systematic.

\section{Rehabilitation}

Pressure ulcers acquired in hospitals or at home often delay rehabilitation; their treatment is costly in terms of time and resources. ICRC orthopaedic centres try to 'hospitalize' these patients, owing to lack of alternatives. Results regarding mobility are good. Wheelchair use can be limited in the domestic terrain (all patients receive one); the focus therefore is on fitting with orthoses and walking with the help of frames or crutches. Close involvement of family caretakers from the start is essential.

Within the available range of methods (and in absence of precise diagnostics), choices made for bladder and bowel management and procedures applied appear correct; indwelling urinary catheters are used as default if empirically tested noninvasive methods fail. Considering the special needs of SCI patients with multiple or severe pressure ulcers and widespread poverty, the high-protein diet provided is vital. Issues of sexual and fertility functions, however, appear relatively neglected.

\section{Community reintegration}

The low implementation rate of policies and laws for the population with disability in Afghanistan has been mentioned. Beyond the 
localized initiatives described in this section, no systematic attempts are made to facilitate community reintegration of SCI individuals. To start with, limited access to health care represents a serious threat to the health of SCI individuals: not one of the interviewed patients mentioned public health services as a provider of care. The disabled in general (similar to the majority of the population ${ }^{3}$ ) seek care from private health providers more frequently than in public health services and their health expenses were found to be four times higher than for the non-disabled. ${ }^{10}$

Anecdotal evidence was found among SCI individuals for the stigma described for the disabled in general in Afghanistan: ${ }^{11}$ a young man not leaving his house for fear of being laughed at, wives discarded by their husbands, and men, formerly the breadwinners of their families, sinking into depression after having become a burden for these. Similar negative attitudes towards the disabled are reported from Pakistan. ${ }^{12}$

A portion of Afghanistan's SCI population benefits from one of the two programmes facilitating community reintegration: communitybased rehabilitation (CBR) implemented by a handful of International NGOs in a number of districts, and ICRC's SCI outreach programmes. Traditional CBR activities conforming with World Health Organization (WHO) guidelines ${ }^{13}$ target all kinds of disabilities, whereas the ICRC programme targets persons with severe physical disabilities only, of which the majority are people with SCI. The latter consists of three inter-related activities: home visits, social programmes and material support. Although the geographical coverage of the first two activities is confined to urban and periurban areas, material assistance is given to all that qualify and present themselves to collect it.

Home visits by a physiotherapist include checking on the individual's health and his or her orthoses, addressing activities of daily living issues, paying attention to pressure sore prevention and early detection of other potential secondary conditions. Specific exercises can be shown as part of the on-going rehabilitation process. Social programmes include home education, vocational training, microcredits and job placement. Material assistance includes house adaptations, delivery of urinary catheters or condoms, dressing material if needed, and quarterly distributions of staple food for the very poor.

The effect of regular home visits on health and activities of daily living of SCI individuals is best illustrated in trends in the growing cohort of SCI individuals visited in Kabul province over the last 12 years ( $N=190$ in 2000 and 679 in 2011): the appearance and increase of the portion of individuals in the best category (ICRC determines the frequency of home visits to SCI individuals according to one of the four categories - ranging from 'very good' over 'good' and 'fair' to 'poor' - in which the client is placed, using indicators of general health status, presence or absence of secondary conditions, activities of daily living and psychosocial status.) 'very good' (from $0 \%$ in 2000 to $30.3 \%$ in 2011 ) is mirrored in the decrease of the portion in the lowest category 'poor' (from $14.8 \%$ in 2000 to $5.4 \%$ in 2011). The first cohort of home-taught youngsters with SCI will graduate from High School next year; some intend to go to university. Dozens have graduated from specialized courses (for example, English language or computer skills) and vocational training. In Balkh province, for instance, 30 out of 50 vocational training graduates were found 6 months later to have established an income-generating activity based on their training. The default rate among the ones taking a credit for establishing or expanding a small business is below $20 \%$. Job placement has been less successful: most jobs found were within ICRC itself (the vast majority of staff in its orthopaedic centres consists in persons with a physical disability) and some with NGOs or consulates; neither the public nor the private sector has been taking.

\section{DISCUSSION}

\section{Policies}

The two Ministries most relevant for Afghanistan's SCI population (MoPH and Ministry of Labour, Social Affairs, Martyrs and Disabled) act more as focal points for coordination than as implementers, owing to resource constraints. The very low implementation rate of relevant policies and laws comes as no surprise in a country plagued by decades of war, with a resource-strapped public sector. Such findings are not particular to Afghanistan; also in Pakistan, for instance, SCI was judged to not be given due importance. ${ }^{14}$

\section{Epidemiology}

The dearth of data on SCI is a hindrance for formulating and implementing public health policies and strategies. The established figure of a reported annual incidence of SCI from the major rehabilitation organizations-21 per million in 2011-permits at least to compare its magnitude to the annual incidence of 40 per million cited for the United States, ${ }^{15}$ for instance.

The aetiology of SCI among all new ICRC admissions in 2011 $(N=478)$ conforms with expectations at global level regarding the preponderance of traumatic over nontraumatic causes. ${ }^{16}$ As in the rest of South Asia (and most developing countries), falls from height among the traumatic causes are more frequent than road traffic accidents. Acts of violence as the single most frequent cause, however, followed by spinal tuberculosis in second place, are results that differ markedly from the regional aetiological pattern (where falls from height are the most frequent cause $\mathrm{e}^{17-19}$ ). The percentage of acts of violence attributable to actual armed conflict is unknown; it is known though that after decades of war Afghans have taken to resolve interpersonal and intertribal disputes by use of weapons. ${ }^{20}$ According to WHO, Afghanistan belongs to the 22 countries of the world with the highest tuberculosis burden, ${ }^{21}$ which explains the high incidence of spinal tuberculosis.

The male to female ratio of people with SCI observed in 2011 of 3.7:1 is comparable to others reported from South Asia: 4:1, 5.5:1 and 7.5:1 in Pakistan, India and Bangladesh, respectively. ${ }^{14,17,22}$ Although a higher gender ratio could have been expected in Afghanistan (considering the tenet that 'the sex ratio reflects the socio-economic and cultural status of a society' ${ }^{17}$ ), the considerable weight of spinal tuberculosis (expected to be much more gender-indifferent than traumatic causes of SCI) may have contributed to this almost counter-intuitive result. The distribution observed among types of lesion, that is the preponderance of paraplegia over tetraplegia and the much larger portion of complete vs incomplete lesions correspond to the pattern encountered in Pakistan ${ }^{14,19}$ and has to do with poorquality prehospital care.

The bulk of the observed morbidity among SCI individuals is determined by the prevalence of pressure ulcers. Their high prevalence after acute hospitalization is explained by the fact that routine physiotherapy and nursing care (such as changing position) are non-existent even in 'tertiary' hospitals in Kabul. Also in Pakistan and Bangladesh, a prevalence of $39 \%$ and $43 \%$, respectively, with pressure ulcers among newly admitted SCI patients was observed. ${ }^{14,23}$ Pressure ulcers later in the history of SCI patients are grounds for hospitals to refuse patient admission, which is why many end up being 'hospitalized' in ICRC centres. The incidence of UTIs, though not quantified, is made evident by the high portion of deaths due to kidney failure. This is related to the fact that all SCI individuals for whom no empirically tested alternative method (for example, Crédé, Valsalva or urinary condoms) appear to work, are using an indwelling urinary catheter, which is the most prevalent risk indicator for UTI. ${ }^{24}$ 
Among other secondary conditions, depression has been described among SCI individuals in both developed ${ }^{25,26}$ and developing ${ }^{27,28}$ countries. In Afghanistan, it can reportedly become part of a vicious circle leading to increased passivity and neglect. The rarity of thromboembolic complications in (South) Asia has been amply described in the literature. ${ }^{29-31}$

\section{Prehospital and hospital care}

A patient with cervical spine injury is unlikely to survive the careless handling of the spine at the trauma site and a bumpy ride to the hospital. For the same reasons and in conjunction with late hospitalization and less-than-optimal treatment, initially incomplete lesions are liable to become complete. Surviving patients with SCI are then often operated, usually weeks after the traumatic event, which calls in question the effectiveness-and therefore also the indication - of spinal surgery. Moreover, patients and their families often appear to have sought and consented to surgical treatment in the misleading belief that it would restore lost functions. The same phenomena have also been observed in Pakistan, where Rathore et al. ${ }^{32}$ conclude that 'in the absence of large, good-quality studies proving that spinal surgery is better than the conservative management, especially if being performed weeks after injury, all patients with traumatic complete SCI should initially be considered for nonoperative management'. The widespread lack of specific care for and misguided referral of SCI patients allows concluding that knowledge about SCI is limited within the medical community in Afghanistan, a phenomenon described also for India ${ }^{33}$ and Pakistan. ${ }^{14}$

\section{Rehabilitation}

Using other methods than indwelling urinary catheters (which is not the method of choice for long-term bladder management) appears difficult in Afghanistan, as in other developing countries; more individual schemes for bladder management may be explored. Precedents have been created by a small number of wealthy SCI individuals who use disposable catheters for intermittent urinary catheterization. In relation to this and other technical matters, international and regional networking and cooperation is to be strengthened.

\section{Community reintegration}

Long-term outcomes for individuals with SCI are not only determined by the level and extent of neurologic preservation, but also by diverse factors as family support, adjustment and coping, productivity, self esteem, financial stability, education, and the physical and social environment. ${ }^{34}$ In developing countries, social support systems and community reintegration programs for SCI patients are not well established and patients face social, financial and mobility barriers; ${ }^{19}$ also lacking is a major SCI forum where the patients can raise their voices and struggle for their rights. ${ }^{1}$

Obstacles to community reintegration for SCI individuals in Afghanistan appear insurmountable: public services do not exist in rural areas and those available in urban areas are not always adapted to the needs; employment and income generation activities are nonexistent and education and health facilities remain inaccessible. ${ }^{35}$ The high number of SCI individuals seeking treatment for secondary conditions in ICRC centres instead of public hospitals closer to their homes testifies to a relative incapacity of the latter to respond to the needs of the SCI population.

Social hostility against the disabled has been described as a major obstacle to community reintegration in Afghanistan ${ }^{11}$ as well as in neighbouring Pakistan. ${ }^{12}$ Beyond perceptions of people with disabilities as 'seen as half, not complete and sometimes unhealthy', the economic burden persons with disabilities may represent has been identified as a significant cause for stigmatization. ${ }^{35}$ Asking for assistance or accepting traditional charity support derived from religious obligations is often perceived by the recipients as shameful. ${ }^{11}$ As a reflection of their general predicament, women with disabilities are systematically in a worse situation than men in Afghanistan. ${ }^{10}$

In developed and developing countries, long-term follow-up of SCI individuals including outreach services is considered necessary if the initial medical and rehabilitation efforts are to have long-term benefit. $^{36,37}$ This study was neither intended nor able to assess the impact of community-based rehabilitation on people with SCI in Afghanistan. There is significant evidence at individual level, however, that the combined efforts of ICRC outreach services-not the least the fact that a number of people with SCI have moved their domicile in order to benefit from them-can be effective regarding both health outcomes and socio-economic reintegration. Limits to coverage are set by the narrow outreach radius, itself defined by distance and insecurity (ICRC has started exploring alternative, low-profile outreach strategies in order to extend it): at present, it covers $20 \%$ of the roughly 6000 SCI individuals ever rehabilitated over the last 2 decades (without discounting for mortality during this time lapse). Other limits to effectiveness are set by poverty, low level of education, limited accessibility of the public space and to health services, by stigma and traditional gender roles. The outreach services also have the unintended impact of reinforcing the urban-rural inequity for SCI individuals regarding access to general services and opportunities.

Whether or not a rapprochement between the two strategies-CBR for all disabled and ICRC outreach for SCI-will be sought in the future is uncertain. Both have their strong and weak points: the former acts nearer the community and is more inclusive, the latter is more effective for the individual. Neither is financially sustainable, on par with Afghanistan's public health service. ${ }^{3}$

\section{CONCLUSION}

This study has attempted to illustrate the opportunities and limitations for rehabilitating people with SCI in a resource-poor environment. The shortcomings of the necessary care before their rehabilitation, and of support during the post-rehabilitation phase (community reintegration) would condemn stand-alone physical rehabilitation of these individuals to near-irrelevance. Taking on key tasks of these other phases, however (though far from being able to fulfil them completely), comprehensive rehabilitation can provide good results even in a difficult setting such as Afghanistan-longterm commitment and sufficient funding provided. Other key limiting factors (especially insecurity caused by the armed conflict and widespread severe poverty) are largely beyond the control of any organization concerned with the SCI population.

Two questions remain open for the moment in history when lasting peace will reign in Afghanistan. Will the country be willing and able to afford specialized SCI care? If yes, who shall provide it? Peace, unfortunately, is not around the corner, which allows all concerned institutions and organizations to ponder these questions while extending and improving their much needed and appreciated services.

\section{CONFLICT OF INTEREST}

The authors declare no conflict of interest. 


\section{ACKNOWLEDGEMENTS}

We thank the ICRC orthopaedic teams for their support and Dr Farooq Rathore for valuable comments on successive draft versions. This study was sponsered by International Committee of the Red Cross.

1 Rathore FA. Spinal Cord Injuries in the Developing World. In: Stone JH and Blouin M (eds). International Encyclopedia of Rehabilitation 2012. Available from http:/l cirrie.buffalo.edu/encyclopedia/en/article/141/ (accessed 23 March 2012).

2 Giustozzi A. Afghanistan: transition without end-an analytical narrative on statemaking. Working paper 40, Crisis States Research Centre, Development Studies Institute, LSE London, 2008

3 Michael M. Too good to be true? An assessment of health system progress in Afghanistan. Providing Health Care in Severely Disrupted Environments: a Multi-country Study. University of Queensland 2011. Available from www.sph.uq.edu.au/acith (accessed 1 June 2012).

4 Deconinck $\mathrm{H}$. The health condition of spinal cord injuries in two Afghan towns. Spinal Cord 2003; 41: 303-309.

5 MoPH. Essential Package of Hospital Services for Afghanistan-2005/1384: Ministry of Public Health, Islamic Republic of Afghanistan.

$6 \mathrm{MoPH}$. A Basic Package of Health Services for Afghanistan-2010/1389. Ministry of Public Health, Islamic Republic of Afghanistan.

7 Government of Afghanistan. The Constitution of Afghanistan 2004

8 MoLSAMD. AFGHANISTAN NATIONAL DISABILITY ACTION PLAN 2008-2011. Prepared for submission to the Government of the Islamic Republic of Afghanistan by the Ministry of Labor, Social Affairs, Martyrs and Disabled.

9 Islamic Republic of Afghanistan. Afghanistan National Development Strategy. Socia Protection Sector Strategy 2007/8-2012/13.

10 Handicap International. Understanding the challenges ahead. National disability survey in Afghanistan. 2006 Executive summary report by Trani J-F and Bakhshi P. Handicap International, Lyon. Available from http://www.handicap-international.fr/bibliographiehandicap/7Donnees/RapportEtude/understandingChallengeAhead.pdf (accessed 28 April 2012).

11 Altai Consulting. "Afghan Perceptions on Disability" prepared for UNICEF and UNOPS/ CDAP-UNDP/NPAD 2004

12 Rathore FA, New PW, Iftikhar AA. Report on disability and rehabilitation medicine in Pakistan: past, present, and future directions. Arch Phys Med Rehabil 2011; 92 : 161-166.

13 WHO. Community-based rehabilitation guidelines. 2003. Available from www.who.int/ disabilities/cbr/guidelines/en (accessed 28 April 2012).

14 Rathore FA, Hanif S, Farooq F, Ahmad N, Mansoor SN. Traumatic spinal cord injuries at a tertiary care rehabilitation institute in Pakistan. Pakistan J Pak Med Assoc 2008; 58 $53-57$.

15 NSCISC. Spinal cord injury facts and figures at a glance. National Spinal Cord Injury Statistical Center, Birmingham, Alabama (NSCISC), 2011. Available from www.nscisc. uab.edu. (accessed 23 March 2012).

16 Ho C, Wuermser LAM, Chiodo A, Scelza W, Kirshblum S. Spinal Cord Injury Medicine. 1. Epidemiology and Classification. Arch Phys Med Rehabil 2007; 88(3 Suppl 1): S49-S54.

17 Hoque MF, Grangeon C, Reed K. Spinal cord lesions in Bangladesh: an epidemiological study 1994-1995. Spinal Cord 1999; 37: 858-861.

18 Gupta N, Solomon JM, Raja K. Demographic Characteristics of Individuals with Paraplegia in India- A survey. Ind J Physiother Occupat Ther 2008; 2: 24-27.
19 Rathore FA, Mansoor SN. Demographics of Spinal Cord Injuries in Pakistan. In: Movagha VR, Jazayeri SB and Vaccaro AR (eds). Epidemiology of Spinal Cord Injuries. Nova Science Publishers: NY, USA, 2012, in press.

20 Michael M, Meddings D, Ramez S, Gutiérrez-Fisac J-L. Incidence of weapon injuries not related to interfactional combat in Afghanistan in 1996: prospective cohort study. BMJ 1999; 319: 415-417.

21 WHO. Global tuberculosis control 2011. Available from www.who.int/tb/publications/ global_report/2011/gtbr11_full.pdf (accessed 28 April 2012).

22 Gupta J, Solomon J, Raja K. Paraplegia: a postal survey of morbidity trends in India. Spinal Cord 2007; 45: 664-670.

23 Islam MS, Hafez MA, Akter M. Characterization of spinal cord lesion in patients attending a specialized rehabilitation center in Bangladesh. Spinal Cord 2011; 49 783-786.

24 Biering-SØRENSEN F. Urinary tract infection in individuals with spinal cord lesion. Curr Opin Urol 2002; 12: 45-49.

25 Leduc BE, Lepage Y. Health-related quality of life after spinal cord injury. Disabil Rehabil 2002; 24: 196-20.

26 Scelza W, Kirshblum S, Wuermser L-A, Ho C, Priebe M, Chiodo A. Spinal Cord Injury Medicine. 4. Community Reintegration After Spinal Cord Injury. Arch Phys Med Rehabil 2007; 88(3 Suppl 1): S71-S75.

27 Levy LF, Makarawo S, Madvidzire D, Bhebe E, Verbeek N, Parry O. Problems, struggles and some success with spinal cord injury in Zimbabwe. Spinal Cord 1998; 36 213-218.

28 Nwankwo OE, Katchy AU Outcome of a 12-week programme for management of the spinal cord injured with participation of patient's relations at Hilltop Orthopaedic Hospital, Enugu, Nigeria. Spinal Cord 2003; 41: 129-133.

29 Aito S, Abbate R, Marcucci R, Cominelli E. Endogenous risk factors for deepvein thrombosis in patients with acute spinal cord injuries. Spinal Cord 2007; 45 $627-631$

30 Lee HM, Suk KS, Moon SH, Kim DJ, Wang JM, Kim NH. Deep vein thrombosis after major spinal surgery: incidence in an East Asian population. Spine 2000; 25 : 1827-1830.

31 Rathore FA, Hanif S, New PW, Butt AW, Aasi MH, Khan SU. The prevalence of deep vein thrombosis in a cohort of patients with spinal cord injury following the Pakistan earthquake of October 2005. Spinal Cord 2008; 46: 523-526.

32 Rathore FA, Farooq F, Mansoor SN. Non-operative management is superior to surgical stabilization in spine injury patients with complete neurological deficits: some additional perspectives. Surg Neurol Int 2012; 3: 22

33 Pandey VK, Nigam V, Goyal TD, Chhabra HS. Care of post-traumatic spinal cord injury patients in India: an analysis. Indian J Orthop 2007; 41: 295-299.

34 Whiteneck G, Meade M, Dijkers M, Tate D, Bushnik T, Forchheimer M. Environmenta factors and their role in participation and life satisfaction after spinal cord injury. Arch Phys Med Rehabil 2004; 85: 1793-1803.

35 Trani J-F, Bakhshi P, Nor AA, Mashkor A. Disability in Afghanistan: taking a capabilities approach to look at research challenges and policy implications 2007. Available from: www.ucl.ac.uk/lc-ccr/lccstaff/jean-francois-trani/HDCAconf0905.pdf (accessed 23 March 2012).

36 Cox RJ, Amsters DI, Pershouse KJ. The need for a multidisciplinary outreach service for people with spinal cord injury living in the community. Clin Rehabil 2001; 15: $600-606$.

37 Priebe M. Spinal cord injuries as a result of earthquakes: lessons from Iran and Pakistan. J Spinal Cord Med 2007; 30: 367-368.

38 Kirshblum SC, Burns SP, Biering-Sorensen F, Donovan W, Graves D E, Jha A et al. International standards for neurological classification of spinal cord injury (Revised 2011). J Spinal Cord Med 2011; 34: 535-46. 